$\Phi=$

\title{
The level of matrix metalloproteinase-9 in the serum as a prognostic sign in extrasphincteric fistulas of the rectum
}

\author{
Zoya I. Mishura ${ }^{1}$, Ruslan K. Paliyenko ${ }^{1}$, Nizar R. Kerbazh ${ }^{1}$ \\ ${ }^{1}$ Institutional mailing address: Poltava State Medical University, 36011, Poltava, 23 Shevchenko Street, Ukraine \\ *Corresponding author E-mail: dr.kerbazh@gmail.com
}

\begin{abstract}
Background. Acute or chronic rectal fistulas make up to $30 \%$ of proctologic pathology and are accompanied by significant impairment of patients` lives. In recent years, the role of matrix metalloproteinases in the pathogenesis of many diseases has grown rapidly. The most widely expressed protease in inflamed tissues is matrix metalloproteinase-9 (MMP-9).

Objectives. To identify and analyze changes in the level of MMP-9 in the serum of patients with extrasphincteric fistulas of the rectum, depending on the method of surgery.

Methods. The study involved 28 patients with extrasphincteric rectal fistulas, who undergone surgery in the proctology department of Poltava Regional Clinical Hospital and the surgical department of the 3rd city clinical hospital in Poltava from 2010 to 2018 . The patients were divided into 2 groups according to the method of surgical treatment. Quantitative determination of MMP-9 in blood serum was performed.

Results. In the main group, the average value of MMP-9 before surgery was $14.90 \pm 0.15 \mathrm{ng} / \mathrm{ml}$, a month later it decreased to $7.73 \pm 0.37$ $\mathrm{ng} / \mathrm{ml}(\mathrm{p}<0.0001)$, and after three months, the average value of MMP-9 was determined at $2.41 \pm 0.13 \mathrm{ng} / \mathrm{ml}(\mathrm{p}<0.0001)$. In the comparison group, the initial average value was $15.00 \pm 0.08 \mathrm{ng} / \mathrm{ml}$, which decreased to $11.89 \pm 0.26 \mathrm{ng} / \mathrm{ml}(\mathrm{p}<0.0001)$, and three months after surgery it decreased to $4.14 \pm 0.17 \mathrm{ng} / \mathrm{ml}(\mathrm{p}<0.0001)$.

Conclusion. The use of MMP-9 levels in blood serum before and after surgery has determined that the method of treatment of extrasphincteric fistulas using the drug Tachocomb is less traumatic and reduces the healing time of postoperative wounds compared to the ligature method.
\end{abstract}

Keywords: Metalloproteinase; Proctology; Rectal Fistula; Tahocomb.

\section{Introduction}

The presence of acute or chronic rectal fistula is a common surgical pathology that occurs in 20-30\% of cases, which is accompanied by frequent recurrences, impaired anorectal function, and significantly impairs the quality of life of the patient. Extrasphincteric fistulas most often occur proximal to the rectum and are usually the result of a procedure or acute paraproctitis and lead to irreversible destruction of the sphincter, perianal tissues, the emergence of chronic paraproctitis (1). They are characterized by a long torturous fistulous course, going around the outer sphincter, the inner hole of which is in the area of the crypt, purulent inflows, scars (2).

In recent years, the number of scientific publications on the role of matrix metalloproteinases in the pathogenesis of many diseases, including diseases accompanied by the development of intestinal inflammation, dysfunction of the intestinal epithelial barrier, has grown rapidly. Matrix metalloproteinases are a family of zinc-dependent endopeptidases that play a significant role in the regulation of both physiological (angiogenesis, embryogenesis, morphogenesis, wound healing, etc.) and pathological processes (inflammation, tumor progression, degenerative processes, etc.) (3).

The most widely expressed protease in inflamed tissues is matrix metalloproteinase 9 (MMP-9), or gelatinase B, which is synthesized by various cells, such as epithelial, dendritic, T-cells, fibroblasts, keratinocytes, osteoblasts, macrophages. It is responsible for the degradation of denatured collagen (gelatin) and basement collagen. Due to its proteolytic activity, MMP-9 is involved in the proteolytic degradation of the extracellular matrix, the cleavage of proteins on the cell surface, proteins of the extracellular environment, leading to tissue remodelling (4,5). MMP-9 is involved in inflammatory processes and has both pro- and anti-inflammatory activities.

\section{The aim of study}

To identify and analyze changes in the level of MMP-9, as an important pathogenic factor, in the serum of patients with extrasphincteric fistulas of the rectum, depending on the method of surgery. 


\section{Materials and methods}

The study involved 28 patients with extrasphincteric fistulas of the rectum of varying severity, who were hospitalized in the proctology department of Poltava Regional Clinical Hospital and the surgical department of the 3rd city clinical hospital in Poltava from 2010 to 2018. Patients with congenital fistulas, fistulas resulting from trauma, tuberculous and actinomycotic etiology were not included in the study. Clinical information was collected for each patient, typical examinations for rectal fistula were performed (examination of the perineum in the patient's lateral position, finger examination of the rectum, fistula examination with a button probe or dye test, rectoromanoscopy or anoscopy).

In the given study, voluntary written informed consent was obtained from all patients.

The patients were divided into groups according to the method of surgical treatment: the main/basic study group included 14 patients operated on the new method using the drug "Tachocomb" (Takeda Austria, Austria); the comparison group also consisted of 14 patients who were operated with ligature method.

Quantitative determination of MMP-9 in blood serum was performed on the basis of the Research Institute of Genetic and Immunological Foundations of Pathology and Pharmacogenetics of Poltava State Medical University. The concentration was determined by solidphase enzyme-linked immunosorbent assay using the commercial kit "Human MMP-9 Platinum ELISA" ("eBioscience", Austria). The study was performed in dynamics three times: the first time the patient's blood was taken after admission to the hospital before surgery, the second - one month after surgery, and the third - three months after surgery.

Peripheral venous blood sampling was performed under sterile conditions from the ulnar vein using a disposable sterile vacuum blood collection system with a coagulation activator and separate SST IITM Advance gel (BD Vacutainer®, UK). To obtain serum, blood samples were allowed to settle for 30 minutes after collection at room temperature for coagulation. The blood samples were then centrifuged at $3000 \mathrm{rpm}$ for 10-15 minutes at room temperature. The serum obtained in this way was stored until analysis at a temperature of $-80^{\circ} \mathrm{C}$. Statistical processing of the results was performed using non-parametric statistics using the statistical software package STATISTICA for Windows (StatSoft Inc., USA), version 10. Differences were considered significant at $p<0,05$.

\section{Research results and their discussion}

The analysis of clinical data showed that most often $(86.2 \%)$ the external fistula hole was located in the projection of the postoperative scar of the previously undergone surgery in the area of the dentate line. The internal hole was located in the posterior crypt in $68.9 \%$ of patients, in another $31.1 \%$ of patients - in the anterior crypt. $87 \%$ of patients had one external fistula. In other patients, we observed from 2 to 5 external fistulous openings.

MMP-9 is an important pathogenic factor in inflammatory diseases. Scientific publications note its increased level in such inflammatory bowel diseases as Crohn's disease, ulcerative colitis, which is accompanied by impaired intestinal barrier function and increased permeability (6).

In our study of enzyme-linked immunosorbent assay of MMP-9 in the serum of patients with extrasphincteric fistulas, we obtained results that indicate a significant decrease in MMP-9 between blood samples in the dynamics in each group (see Table 1).

Table 1: Evaluation of the Results of Determining the Average Concentration of MMP-9 in Patients with Extrasphincteric Fistulas

\begin{tabular}{llll}
\hline Groups & Before surgery & A month after surgery & Three months after surgery \\
\hline main/basic study group & $14,90 \pm 0,15$ & $7,73 \pm 0,37^{*}$ & $2,41 \pm 0,13^{* *}$ \\
comparison group & $15,00 \pm 0,08$ & $11,89 \pm 0,26^{*}$ & $4,14 \pm 0,17^{* *}$ \\
& $\mathrm{p}=0,57$ & $\mathrm{p}<0,0001$ & $\mathrm{p}<0,0001$ \\
\hline
\end{tabular}

* -The significance of the difference compared to the pre-operation indicator, $\mathrm{p}<0.0001$;

** -The significance of the difference compared to a month after surgery, $\mathrm{p}<0.0001$.

Thus, in the main group, the average value of MMP-9 before surgery was $14.90 \pm 0.15 \mathrm{ng} / \mathrm{ml}$, a month later it decreased twice - to $7.73 \pm$ $0.37 \mathrm{ng} / \mathrm{ml}(\mathrm{p}<0.0001)$, and after three months, the average value of MMP-9 was determined at $2.41 \pm 0.13 \mathrm{ng} / \mathrm{ml}(\mathrm{p}<0.0001)$. In the comparison group, there was also a significant decrease in the mean value of MMP-9, although not as fast. In the initial study, the average value was $15.00 \pm 0.08 \mathrm{ng} / \mathrm{ml}$, which decreased to $11.89 \pm 0.26 \mathrm{ng} / \mathrm{ml}(\mathrm{p}<0.0001)$, and three months after surgery it decreased to 4.14 $\pm 0.17 \mathrm{ng} / \mathrm{ml}(\mathrm{p}<0.0001)$.

As can be seen from the table, the initial (before surgery) average concentrations of MMP-9 were the same in both groups ( $p=0.57$ ). We obtained statistically significant differences when comparing the average concentrations of MMP-9 one month $(\mathrm{p}<0.0001)$ and three months $(\mathrm{p}<0.0001)$ after surgery between the main/basic group and the comparison group.

During inflammation and degradation of collagen of the basal intestinal wall, MMP-9 is one of the important proteases which is the most widely, of all matrix metalloproteinases, expressed by inflammatory cells of the intestine and correlates with the activity of inflammatory disease $(7,8)$.

Thus, according to our data, the concentrations of MMP-9 were significantly lower during surgical treatment by the new method, and they decreased significantly for three months after surgery in both groups, which can be considered as a favorable prognostic and diagnostic sign. The method of treatment of extrasphincteric fistulas using the drug Tachocomb is less traumatic and reduces the healing time of postoperative wounds compared to the ligature method.

\section{References}

[1] Jimenez M, Mandava N. Anorectal Fistula. In: StatPearls [Internet] Treasure Island (FL): StatPearls Publishing [Internet]. Treasure Island (FL): StatPearls Publishing; 2021. Available from: https://pubmed.ncbi.nlm.nih.gov/32809492/

[2] O. V Popkov, S. A. Alekseev, V. G. Bogdan RECTAL FISTULA. FEATURE OF DIAGNOSIS AND TREATMENT. Lech Vopr. 2014; 4:60-3.

[3] Cui N, Hu M, Khalil RA. Biochemical and Biological Attributes of Matrix Metalloproteinases. Prog Mol Biol Transl Sci. 2017; $147: 1-73$. https://doi.org/10.1016/bs.pmbts.2017.02.005.

[4] Goffin L, Fagagnini S, Vicari A, Mamie C, Melhem H, Weder B, et al. Anti-MMP-9 Antibody: A Promising Therapeutic Strategy for Treatment of Inflammatory Bowel Disease Complications with Fibrosis. Inflamm Bowel Dis. 2016 Sep; 22(9):2041-57. https://doi.org/10.1097/MIB.0000000000000863. 
[5] Huang H. Matrix Metalloproteinase-9 (MMP-9) as a Cancer Biomarker and MMP-9 Biosensors: Recent Advances. Sensors (Basel). 2018 Sep; 18(10). https://doi.org/10.3390/s18103249.

[6] Al-Sadi R, Youssef M, Rawat M, Guo S, Dokladny K, Haque M, et al. MMP-9-induced increase in intestinal epithelial tight permeability is mediated by p38 kinase signaling pathway activation of MLCK gene. Am J Physiol - Gastrointest Liver Physiol. 2019; 316(2):G278-90. https://doi.org/10.1152/ajpgi.00126.2018.

[7] Koelink PJ, Overbeek SA, Braber S, Morgan ME, Henricks PAJ, Abdul Roda M, et al. Collagen degradation and neutrophilic infiltration: a vicious circle in inflammatory bowel disease. Gut. 2014 Apr; 63(4):578-87. https://doi.org/10.1136/gutjnl-2012-303252.

[8] Mäkitalo L, Piekkala M, Ashorn M, Pakarinen M, Koivusalo A, Karikoski R, et al. Matrix metalloproteinases in the restorative proctocolectomy pouch of pediatric ulcerative colitis. World J Gastroenterol. 2012; 18(30):40 28-36. https://doi.org/10.3748/wjg.v18.i30.4028. 